\title{
Production of Austenitic Steel for the LHC Superconducting Dipole Magnets
}

\author{
F. Bertinelli, F. Fudanoki, T. Komori, G. Peiro, and L. Rossi
}

\begin{abstract}
The austenitic-steel collars are an important component of the LHC dipole magnets, operating at cryogenic temperature under high mechanical stress. The required steel, known as YUS 130S, has been specifically developed for this application by Nippon Steel Corporation (NSC), who was awarded a CERN contract in 1999 for the supply of 11500 tonnes.

In 2005-after six years of work-the contract is being successfully completed, with final production being ensured since October 2003 by Nippon Steel \& Sumikin Stainless Steel Corporation (NSSC).

The paper describes the steel properties, its manufacturing and quality control process, organization of production, logistics and contract follow-up. Extensive statistics have been collected relating to mechanical, physical and technological parameters.

Specific attention is dedicated to measurements of magnetic permeability performed at cryogenic temperatures by CERN, the equipment used and statistical results.
\end{abstract}

Reference is also made to the resulting precision of the fine-blanked collars.

Index Terms-Structural materials for S.C. magnets.

\section{INTRODUCTION}

A USTENITIC steel with low magnetic permeability and high strength is the material used for the collars that confine and pre-stress the coils of the LHC superconducting dipole cold masses so that they maintain their precise geometry in spite of the high electromagnetic forces occurring during magnet operation at $1.9 \mathrm{~K}$ cryogenic temperature [1]. In order not to lose the coil pre-stress introduced during assembly at room temperature, the steel must have a thermal expansion coefficient similar to that of copper [2], [3]. 11500 tonnes of steel are supplied as coils to produce over 11800000 collars-two main types 1 and 2 according to geometry-for 1278 dipoles. These collars are produced using fine-blanking technology by two European suppliers, allowing to achieve the specified geometric precision for large series quantities at competitive costs.

In this paper we report on the six-year steel production experience and present extensive statistics on physical, mechanical and technological properties.

\section{STEEL PRODUCTION}

\section{A. The YUS 130S Austenitic Steel}

The austenitic steel-known under the trade name YUS $130 \mathrm{~S}$ - is a production of Nippon Steel \& Sumikin Stainless

Manuscript received September 19, 2005.

F. Bertinelli, G. Peiro, and L. Rossi are with the AT Department, CERN, Geneva, Switzerland (e-mail: Francesco.Bertinelli@cern.ch).

F. Fudanoki and T. Komori are with NSSC, Japan.

Digital Object Identifier 10.1109/TASC.2006.873244

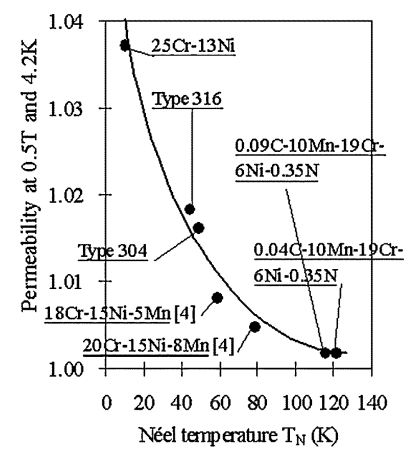

(a)

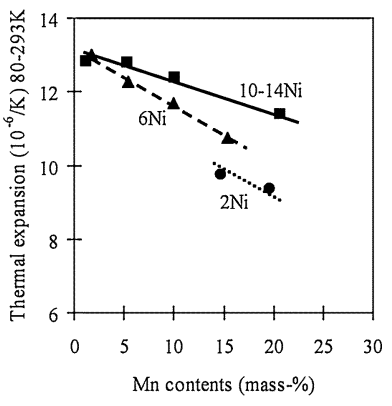

(b)
Fig. 1. (a) Relationship between magnetic permeability and Néel temperature [5], [6]; (b) effects of Mn and Ni content on the average thermal expansion of $0.1 \mathrm{C}-19 \mathrm{Cr}-0.35 \mathrm{~N}-\mathrm{Mn}-\mathrm{Ni}$ steels [6].

Steel Corporation (NSSC). It is a stainless steel $\mathrm{X} 8 \mathrm{CrMnNiN}$ 19-11-6 grade.

The principal properties of YUS 130S-low magnetic permeability, high thermal expansion coefficient and high strength at cryogenic temperature-are obtained by an adequate balance of $\mathrm{Mn}$ and $\mathrm{Ni}$ content.

The magnetic permeability $\mu_{\mathrm{r}}$ is directly related to the Néel temperature $\mathrm{T}_{\mathrm{N}}(\mathrm{K})$ - at which the metallurgical transition between paramagnetic and antiferromagnetic behavior occurs at cool down - that in turn depends on chemical composition (\% weight) [4]:

$$
\begin{aligned}
\mathrm{T}_{\mathrm{N}}(\mathrm{K})=99.81- & 1.37 \mathrm{Cr}-3.14 \mathrm{Ni}+8.83 \mathrm{Mn} \\
- & 12.68 \mathrm{Si}+4.48 \mathrm{Mo}-32.45 \mathrm{C}-33.86 \mathrm{~N}
\end{aligned}
$$

Fig. 1(a) shows that the LHC specification of $\mu_{\mathrm{r}} \leq 1.003$ for $0.1 \mathrm{~T}$ at $1.9 \mathrm{~K}$ is approximately related to $\mathrm{T}_{\mathrm{N}}>100 \mathrm{~K}$ and consequently a high Mn content or a low Ni content.

Fig. 1(b) shows the effect of $\mathrm{Mn}$ and $\mathrm{Ni}$ on the average thermal expansion coefficient between $80 \mathrm{~K}$ and $293 \mathrm{~K}$, and consequently a conflicting requirement for low Mn content or high Ni content.

This simplified argument-neglecting contributions to $\mu_{\mathrm{r}}$ due to ferritic or martensitic phases possibly present in the austenitic matrix-guided the development of YUS 130S, achieving a compromise between $\mathrm{Mn}$ and $\mathrm{Ni}$ content with a composition $0.09 \mathrm{C}-18 \mathrm{Cr}-7 \mathrm{Ni}-11 \mathrm{Mn}-0.3 \mathrm{~N}$.

\section{B. The LHC Production of YUS 130 S}

The steel is delivered to CERN in coil form, nominal thickness $3 \mathrm{~mm}$, typical mass $2200 \mathrm{~kg}$.

The production process involves several operations performed in different sites (Hikari and Yawata Works):

- Production of cast iron; 
- Steel conversion, typically with $60 \mathrm{t}$ melts, using electric furnace and refining treatment by argon-oxygen decarburization;

- Continuous casting, producing typically $12 \mathrm{t}$ slabs, thickness $200 \mathrm{~mm}$, width $865 \mathrm{~mm}$;

- Continuous hot rolling to a thickness $6 \mathrm{~mm}$;

- Hot coil annealing and pickling;

- Coil grinding to remove surface defects - this proved to be the main production bottleneck;

- Cold rolling by 20-rollers Sendzimir mill to produce mother coils, width $820 \mathrm{~mm}$, thickness $3 \mathrm{~mm}$;

- Final annealing and pickling;

- Skin-pass rolling to improve coil flatness;

- Slitting to produce 4 final coils width $410 \mathrm{~mm}$ from each mother coil.

- Extensive sampling for quality control is performed during slitting. Each coil-over 5000 coils were delivered-is uniquely identified and full traceability - both for technical and logistic features-is ensured by NSSC, CERN and the fine-blankers.

Transport from Japan to Europe-by boat then road to CERN-required over 600 standard 20 -feet containers with door at one end-representing a cost of $8 \%$ of the ex-works steel price. The coils were unloaded and stored at CERN, then transported to the fine-blankers by truck.

\section{Physical and Chemical Measurements}

\section{A. Equipment for 4.2 K Magnetic Measurements at CERN}

The permeability $\mu_{\mathrm{r}}$ is measured at CERN both at room temperature and at $4.2 \mathrm{~K}$.

Measurements at room temperature are performed with an industrial Förster magnetoscope at a field of $\sim 0.1 \mathrm{~T}$ that requires a minimum material thickness of $8 \mathrm{~mm}$ : values measured on smaller thicknesses are lower than the real permeabilities. This is a fast, simple quality control to roughly identify potential problems. Typical values for YUS $130 \mathrm{~S}$ fall in the range $\mu_{\mathrm{r}}=1.0015$ to 1.0020 : lower figures are for single $3 \mathrm{~mm}$ sheets, higher figures for stacked $3 \mathrm{~mm}$ sheets.

Much more detailed measurements are made at $4.2 \mathrm{~K}$ using a purpose-built equipment designed at CERN, see Fig. 2. The system consists of a low- $\mu$ permeameter inserted into a vertical cryostat, a power supply and a superconducting solenoid. The measurement procedure has been automated using LabView.

Great care is needed in the sample preparation (dimensions 5 $\mathrm{mm} \times 3 \mathrm{~mm}$, length $40 \mathrm{~mm}$ ), to avoid introducing heat or permanent deformation that can cause degradation to the magnetic properties. Spark erosion is used followed by a light chemical cleaning to remove oxide residues.

Eight samples can be loaded on a holder insert and revolved individually into the measurement position.

The relative permeability of the samples is then measured, see Fig. 3. The detection coil with $\sim 12000$ turns is placed inside a homogeneous field generated by the superconducting solenoid, in a range of flux density from $0.1 \mathrm{~T}$ to $8 \mathrm{~T}$. The voltage-proportional to $\mu_{\mathrm{r}}$-is integrated and measured. The lower measurement limit is at $0.1 \mathrm{~T}$, where the useful signal is less than $200 \mu \mathrm{V}$ and integrators use the maximum possible gain (1000) becoming unstable.

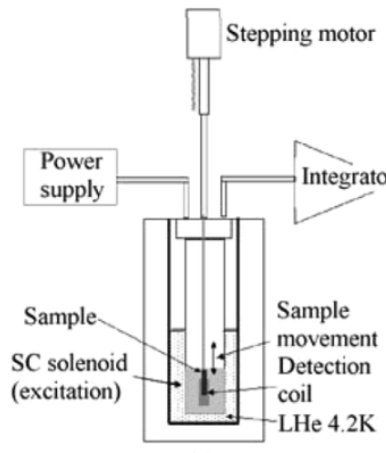

(a)

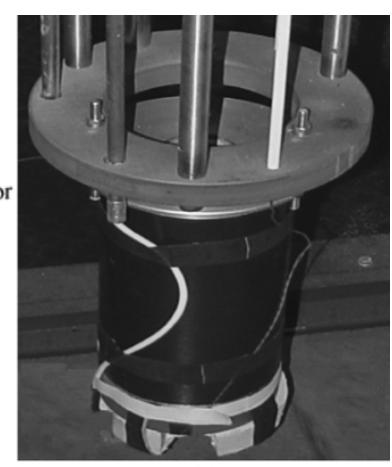

(b)
Fig. 2. (a) The CERN $4.2 \mathrm{~K}$ permeability measuring system; (b) the superconducting solenoid.

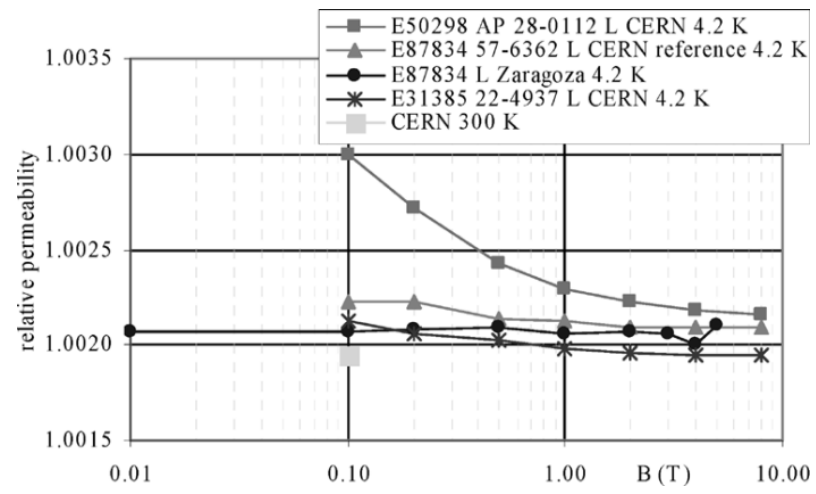

Fig. 3. CERN measurements of relative permeability at $4.2 \mathrm{~K}$ and RT, examples for different melts, longitudinal direction.

The precision of measurement has been analyzed. Systematic errors have been limited by calibration against a reference sample [7]. Repeatability—referring to successive measurements on the same sample in the same session-has been investigated. Reproducibility - referring to measurements of the same sample in different sessions-is monitored by systematically re-measuring a reference sample. Overall the precision on $\left(\mu_{\mathrm{r}}-1\right)$ is considered $\pm 10.1 \%$ at $0.1 \mathrm{~T}$ and $\pm 3.1 \%$ at $1 \mathrm{~T}$.

\section{B. Magnetic Measurements of YUS 130S}

The monitoring of permeability at $4.2 \mathrm{~K}$ during production was ensured by the Universidad de Zaragoza and CERN: results for other austenitic cryogenic steels are also available.

The measuring samples are obtained from $410 \mathrm{~mm} \times 210 \mathrm{~mm}$ steel samples supplied by NSSC for each melt.

The Universidad de Zaragoza uses a commercial SQUID magnetometer with a precision on $\left(\mu_{\mathrm{r}}-1\right)$ considered better than 1\%: the sample size is smaller than CERN (dimensions 3 $\mathrm{mm} \times 4 \mathrm{~mm}$, length $6 \mathrm{~mm}$ ). They measured $\sim 100$ samples at the start of NSSC production, cut both in the longitudinal and the transverse directions.

Some measurements, $\sim 10$ samples, were initially performed at both $1.8 \mathrm{~K}$ and $4.2 \mathrm{~K}$ : the difference on $\mu_{\mathrm{r}}$ is insignificant, so measurements were continued only at $4.2 \mathrm{~K}$.

Over the $\sim 100$ samples, the difference on $\mu_{\mathrm{r}}$ between longitudinal (rolling) and transverse directions is insignificant, so measurements were continued only on longitudinal samples. 


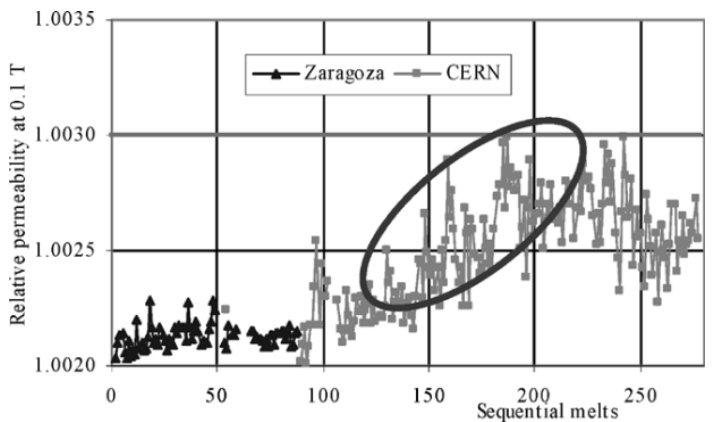

Fig. 4. Universidad de Zaragoza and CERN measurements of permeability at $4.2 \mathrm{~K}$.

TABLE I

Chemical Composition of Melts (\% WeIGHT)

\begin{tabular}{ccccccc}
\hline $\mathbf{C}$ & $\mathbf{M n}$ & $\mathbf{N i}$ & $\mathbf{C r}$ & $\mathbf{M o}$ & $\mathbf{S i}$ & $\mathbf{N}$ \\
\hline 0.086 & 11.5 & 6.61 & 17.77 & 0.09 & 0.42 & 0.30 \\
$(\sigma=0.005)$ & $(\sigma=0.2)$ & $(\sigma=0.06)$ & $(\sigma=0.07)$ & $(\sigma=0.02)$ & $(\sigma=0.04)$ & $(\sigma=0.01)$ \\
\hline
\end{tabular}
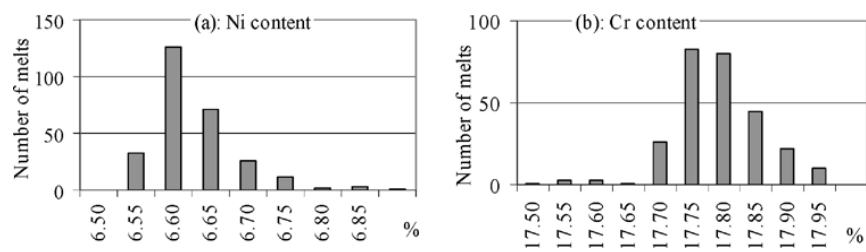

Fig. 5. Statistics on chemical composition, $\mathrm{Ni}$ and $\mathrm{Cr}$.

CERN continued the monitoring of production from 2002 to 2005 with over 150 samples measured.

Fig. 4 shows monitoring of YUS 130S production, with $\mu_{\mathrm{r}}$ at $0.1 \mathrm{~T}$ (average $=1.0024, \sigma=0.0003$ ). A potential problem with $\mu_{\mathrm{r}}$ increasing toward the specified limit was detected by CERN in November 2004 and corrected by NSSC with small adjustments to the chemical composition of the melts.

After performing tensile tests at $4.2 \mathrm{~K}, \mathrm{CERN}$ [8] also tested the effect of plastic strain on permeability at RT (specimen from longitudinal direction, plastic strain values $0.4,2.9,5.4,10.3$ and $20.4 \%, 0.1 \mathrm{~T}$ ). It was noticed that $\mu_{\mathrm{r}}$ degrades rapidly with plastic strain, typically $\mu_{\mathrm{r}} \sim 1.005$ at $10.3 \%$ strain: local plastic deformations were therefore limited by design.

\section{Other Physical and Chemical Measurements}

NSSC reports the chemical composition measured for each melt, by X-ray fluorescence analysis for the metallic elements and gas analysis for the others. Table I summarizes average results for some important elements over $\sim 274$ melts.

The spread in chemical composition is controlled very tightly, see Fig. 5. The chemical composition of $\mathrm{C}$ and Mn was finely adjusted to correct for increasing $\mu_{\mathrm{r}}$ (lowering of $\mathrm{C}$ content to $0.08-0.09 \%$ and increase of $\mathrm{Mn}$ content to $11.50-11.70 \%$ ), see Fig. 6.

The trend of the $\mu_{\mathrm{r}}$ measurements-Fig. 4-follows closely the trend of the NSSC measurements of C content (moving average) Fig. 6(a). This observation-in contrast with existing knowledge at NSSC - deserves further investigations requiring a more precise measurement of $\mathrm{C}$ values.
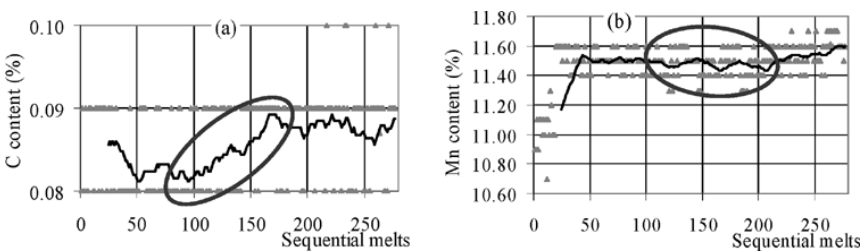

Fig. 6. Precision adjustments in chemical composition (moving averages), (a) for $\mathrm{C}$ and (b) for $\mathrm{Mn}$.
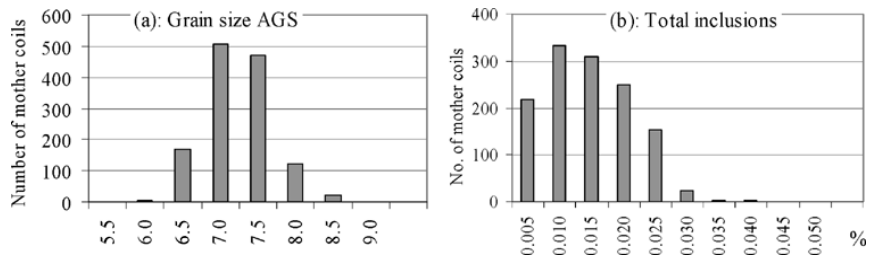

Fig. 7. Statistics on grain structure and inclusions content.

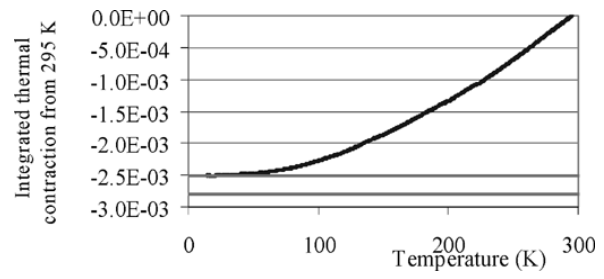

Fig. 8. Thermal contraction curve for a steel sample (melt E46082, mother coil 26-9171) and specification limits at $4.2 \mathrm{~K}$.

NSSC also reports grain size (specified minimum 4 according to the standard JIS G 0551) and inclusions (according to the standard JIS G 0555) measured for each mother coil, see Fig. 7.

Density is an important, often neglected parameter linking the basic requirement of physics - a "volume" of steel inside magnets - with the normal requirement of steel industry - to sell by "mass". This was measured at CERN to be $7.78 \pm 0.01 \mathrm{kgdm}^{-3}$ at $25.5^{\circ} \mathrm{C}$.

The integrated thermal contraction-measured at CERN with dedicated equipment in the temperature range $295 \mathrm{~K}$ to $15 \mathrm{~K}$-is typically $2.5 \times 10^{-3}$, see Fig. 8 .

\section{Mechanical Measurements}

NSSC reports tensile and hardness tests at room temperature performed on samples taken from the start of each mother coil, in the longitudinal direction. Fig. 9 shows statistics for the yield strength (average $=428.0 \mathrm{MPa}, \sigma=13.7 \mathrm{MPa}$ ) and for hardness (average $=211.8 \mathrm{HV}, \sigma=4.5 \mathrm{HV}$ ). The highest stress levels in the collar structure are $\sim 280 \mathrm{MPa}$ occurring both at RT assembly and in operation at $1.9 \mathrm{~K}$.

Tensile tests performed at cryogenic temperatures are summarized in Table II.

\section{TeChnological Measurements}

\section{A. Sheet Geometry}

The specified coil thickness is $3.0 \pm 0.075 \mathrm{~mm}$.

During slitting, thickness measurements are performed mechanically across the coil width, on samples taken from the start, 

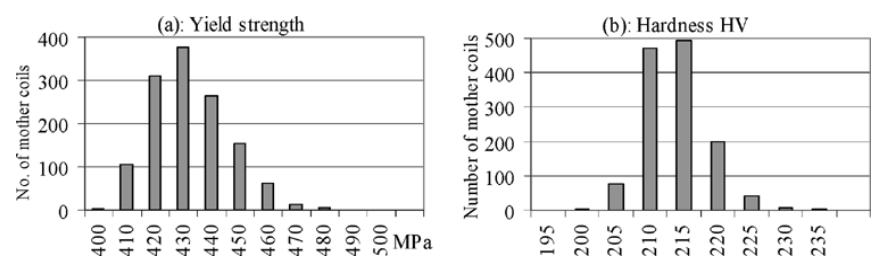

Fig. 9. Statistics on yield strength and Vickers hardness at RT.

TABLE II

NSC AND CERN [8]: Tensile TeSTS AT CRYOGENIC TEMPERATURE, LONGITUDINAL AND TRANSVERSAL ROLLING DIRECTIONS

\begin{tabular}{lccccc}
\hline \hline & $\begin{array}{c}\text { Temperature } \\
(\mathrm{K})\end{array}$ & $\begin{array}{c}\text { Young's } \\
\text { Modulus } \\
(\mathrm{GPa})\end{array}$ & $\begin{array}{c}\text { Yield } \\
\text { Strength } \\
(\mathrm{MPa})\end{array}$ & $\begin{array}{c}\text { Tensile } \\
\text { Strength } \\
(\mathrm{MPa})\end{array}$ & $\begin{array}{c}\text { Elongation } \\
(\%)\end{array}$ \\
\hline L direction & 77 & & 1042 & 1592 & 35 \\
T direction & 77 & & 1103 & 1594 & 29 \\
L direction [7] & 4.2 & 202 & $1360 \pm 35$ & $1881 \pm 8$ & $25.3 \pm 0.4$ \\
T direction [7] & 4.2 & 202 & $1581 \pm 9$ & $1902 \pm 8$ & $24.8 \pm 2.4$ \\
\hline \hline
\end{tabular}
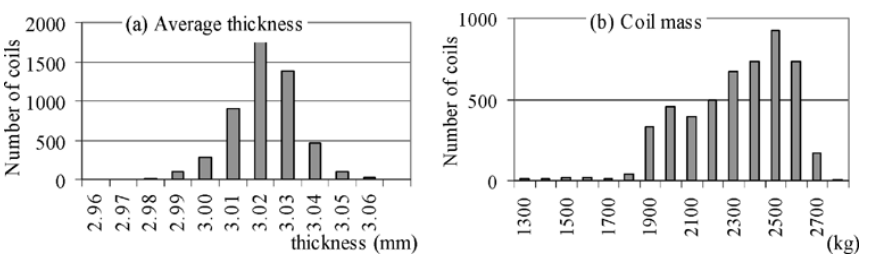

Fig. 10. Statistics on average coil thickness and coil mass.
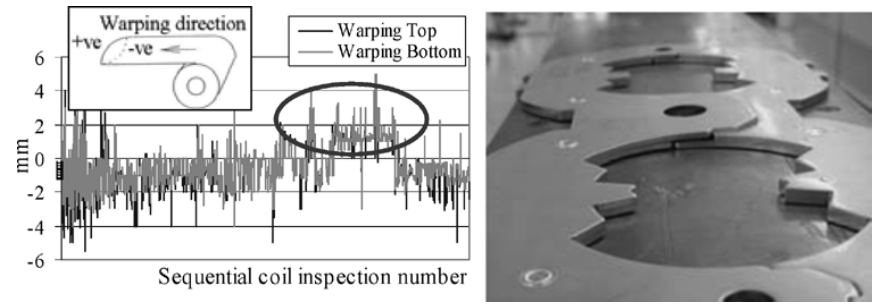

Fig. 11. Statistics on warping and example of poor collar flatness.

middle and end of each coil. The distribution of the weighed average coil thickness (average $=3.017 \mathrm{~mm}, \sigma=0.012 \mathrm{~mm}$ ) and coil mass is shown in Fig. 10.

NSSC also reports geometrical coil data, specifically for flatness (edge and middle wave) and warping, see Fig. 11.

In May 2004 a systematic problem with the flatness of the produced collars was correlated by CERN to a change in warping direction of the coils. The origin was identified with an accidental inversion of coil rewinding direction and corrected. Meanwhile fine-blanking continued by optimizing coil usage: -ve warping for collars type $1,+$ ve for type 2 .

\section{B. Fine-Blanking}

The fine-blankers initially found YUS 130 S a relatively difficult material to work with, because of its hardness and "springi-

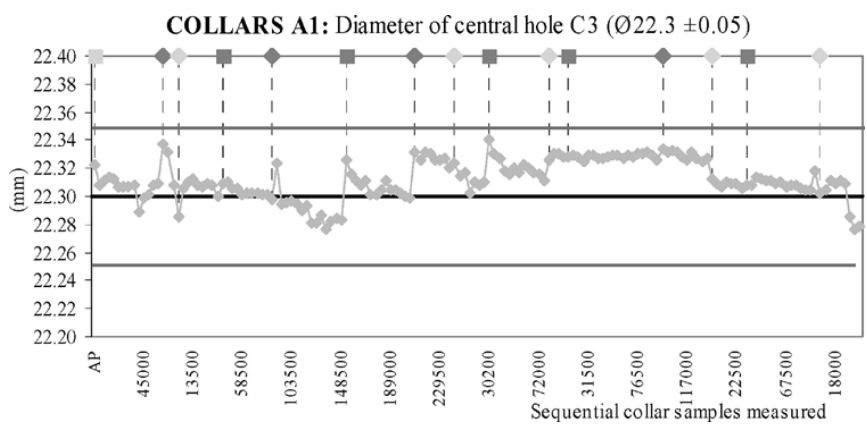

Fig. 12. Collar geometric stability during fine-blanking (6 production campaigns March to July 2005, over 700000 collars): collaring hole diameter, effect of wear between tool changes [9].

ness". The geometric precision of collars required good stability of the material, see Fig. 12. Each dipole requires steel from $\sim 4$ coils: no collar mixing was necessary.

The surface defects encountered concern exceptionally traces of rust deposited by the steel coil straps: YUS $130 \mathrm{~S}$ proved to have an excellent rust resistance. No protective interleaved paper was considered necessary.

An optimization work with NSSC and the fine-blankers allowed considerable savings by limiting the scrapped steel to 30 $\mathrm{cm}$ at start and $60 \mathrm{~cm}$ at end of coils length $\sim 230 \mathrm{~m}$.

\section{CONCLUSION}

The production of $11500 \mathrm{t}$ of YUS 130S has been successfully completed and the specified characteristics-specifically at cryogenic temperatures-obtained.

\section{REFERENCES}

[1] L. Rossi, "Experience with LHC magnets from prototyping to large scale industrial production and integration," in EPAC 2004, Lucerne, Switzerland, July 5-9, 2004.

[2] C. Lanza and D. Perini, "Characteristics of the austenitic steels used in the LHC main dipoles," IEEE Trans. Appl. Supercond., vol. 12, no. 1, Mar. 2002.

[3] C. Lanza and D. Perini, "Characteristics of the austenitic steels used in the LHC main dipoles," in MT17, Geneve, Switzerland, Sept. 24-28, 2001.

[4] E. R. Jones, Jr., T. Datta, C. Almasan, D. Edwards, and H. M. Ledbetter, Mater. Sci. Eng., vol. 91, p. 181, 1987.

[5] T. Takemoto, "Mechanical and magnetic properties of Cr-Ni austenitic stainless steel at cryogenic temperature" 1988, vol. 58, p. 11, Nisshin Steel Tech. Rep.

[6] H. Sumitomo and J. Nakatuka, "Development of high-strength nonmagnetic stainless steel for cryogenic services," Proc. Int. Conf. Stainless Steels. Chiba, ISIJ, p. 480, 1991.

[7] Private communication, Servicio de Instrumentation Cientifica, Area de medidas magneticas, Universidad de Zaragoza.

[8] K. Couturier and S. Sgobba, "Phase stability of high manganese austenitic steels for cryogenic applications," in Proc. Materials Week 2000 Conf., Munich, Germany, Sep. 25-28, 2000.

[9] Private communication, Ernesto Malvestiti SpA, Cinisello Balsamo (MI), Italy. 